\title{
SIGNIFICANCE OF EARLY-AGE LEARNING OF MATHEMATICAL SKILLS
}

\author{
Sead Rešić1 \\ Amir Suljičić \\ Faculty of Science, University of Tuzla
}

Received: 11.06.2011

Accepted: 23.10.2011
Professional paper

UDC: $159.953 .5: 51-053.4 / .5$

\begin{abstract}
It is a fact that only hereditary, i.e. genetic factors are not sufficient for development of a child's brain; on the contrary, a child needs external stimuli expressed through touch, speech, images, which lead to the conclusion that immediate and extended surroundings shape the brain, meaning that the external stimuli, stronger or weaker, mutually connect the brain cells and neurons.

Questions regarding the development of mathematical manner of thinking are mostly based on the natural process of learning, however, this paper deals with deeper set of problems, which are not only difficult to resolve but possibly there is no resolution. Namely, a question is posed what is the appropriate age when a child is ready and able to solve certain mathematical problems or notice mathematical principles, that is, whether they are actually exist clearly defined age boundaries based on which a conclusion could be made about the time and individual is ready to solve mathematical problems of a concrete difficulty level or to notice mathematical laws.
\end{abstract}

Key words: mathematics, cognition, learning process, mathematical skills, teaching process, scientific process

\section{INTRODUCTION}

Regardless of the requests of this galloping, demanding, competition-wise, thoughtless phenomenon named globalization of society, it should not be forgotten that every child should unprincipled visually experience every mathematical problem, of course, if that is a possibility (arranging dice, grouping sticks together, playing educational games such as tangram, abacus, etc.) and only register the image which should be sketched based on the visual experience (the form of a square, triangle, circle, etc.) and then to conjoin the sketched elements with symbols, i.e. numbers.

Unavoidable fact is "that children are born intelligent" and that even before enrolling in school most of them are familiar with elementary mathematical operations such as adding, subtracting, multiplying and dividing, of course, parents are extremely satisfied since they are in great part the ones who helped the development of physical as well as intellectual levels of their children.

1 Correspodence to:

Sead Rešić, Faculty of Philosophy, University of Tuzla

Šabana Zahirović 10, Tuzla, B\&H

Phone: +38761101230

E-mail: sresic@hotmail.com 
The notion of number expressed in the form of a figure as well as mathematical operations, are based on memorizing and reproduction in children, thus since they are acquired as such they cannot represent fertile soil for developing creative thinking and resourcefulness in unfamiliar situations, and mathematics is abundant with those. Seldom does a parent ask himself or herself "how does my child accept abstract notions such as what is a number or a certain operation." It is a very frequent occurrence that a great number of high school students, due to the abstractness of their notions of operations accept the mathematical formulation $2 \mathrm{a}+2 \mathrm{~b}$ as $4 \mathrm{ab}$ or in some other way. Many years of work conducted by people, as well as a lot of problems they encountered in their work represented a condition for development of mathematics and mathematical skills, which is evident even today and there are no indications that it will ever stop developing. Thanks to its exactness, mathematics is deeply rooted in the laws of nature, society, manners of thinking, thus justifying the functions, proving the laws and structures confirming or deputing the rules.

\section{JEAN PIAGET, DEVELOPMENTAL STADIUMS OF CHILDREN'S COGNITIVE DEVELOPMENT}

\section{Stadium of characteristics}

Sensory-motoric stadium (from birth till the second year of life)

Form of intelligence in which knowledge is based on bodily interaction with people and objects.

The most significant role is attributed to experiences related to sensory organs (sight, hearing, touch, taste, smell). The notion of object permanence: Objects have permanence which is independent of our perceptive interaction with them (18-24 months of age).

\section{Stadium of pre-operative thinking (2-6 year of age)}

Form of intelligence where symbols and mental activities begin to replace objects and external behavior.

Speech appears and the symbolic function slowly begins (the things the child talks about do not have to be directly present). The child is able to draw (even though not completely logically correct, certain conclusions. Now there is ego- egocentricity, animity, artificiality. Form of symbolic functions are: delayed imitation, symbolic play, imaginary friend.

Stadium of concrete operations (6-11 years of age) Form of intelligence in which mental operations enable logical problem solving with concrete objects. This manner of thinking Piaget calls "concrete operations", because operations that demand thinking are performed on objects, where the existence of perceptive information is still necessary. During this stadium there are operations: classification, seriation, conservation of notions such as number, quantity and weight, conservation of the notion of space and time and cetera.

\section{Stadium of formal/logical operations (age 11 and} farther)

Form of intelligence where mental operations of a higher degree enable logical reasoning as opposed to abstract and hypothetical events and not only concrete objects.

During this period a child thinks and crates judgments based on verbally formulated hypotheses. Thanks to that, the child is able to separate itself from concrete objects and solve the task. In this period thinking acquires characteristics of that in adults, which implies performing thinking operations with abstract symbols and notions, in imagined and hypothetical situations. 
SENSORY-MOTORIC STADIUM, STADIUM OF THE CHARACTERISTIC

First stadium: Practicing reflexes (from birth up to one month)

Child is limited to performing congenital reflexes (grabbing and sucking).

Piaget believes that the repertoire of adjustments in a newborn's behavior is limited to simple, biologically determined reflexes. Such initial behaviors are extremely significant because they represent the foundations of the future development. Through processes of assimilation and accommodation occur changes in the initial rigid behavior because of new experiences, therefore the child enters the second sensory-motoric stadium.

Second stadium: Developing of schemata (1-4 months)

Reflexes turn into adaptive schemata. Schemata are developed and modulated.

Sensory-motoric schemata: rehearsed and generalized sets of responses through which the child acts and learns to understand the surrounding world. According to Piaget's theory, those are cognitive structures of early childhood.

That is why, for example, we can talk about "the sucking scheme" since the child has an organized pattern for sucking, which can be applied to numerous different stimuli. Of course, the nipples are sucked, but also toys, rattles, fingers.

Third Stadium: Techniques of discovering (4-8 months).

Behavior becomes more and more directed outwards. Child develops techniques to experience interesting events again.

Even though small children affect their surroundings from the very birth, during the first months their behavior is directed inwards. For example, when a toddler holds a toy, it seems that is more interested in finger movements then the toy itself. During the second developmental stadium, a child employs schemata from a pure satisfaction grabs because of grabbing itself, sucks for the sake of sucking, while the during the third stadium the child exhibits clear interest for the outside world.

Schemata begins to shift from being directed at the child's body to explorations of surroundings (i.e. it plays with toy because of true interest for exploring the object).

\section{Fourth stadium: Deliberate behavior (from eighth} to twelfth month)

The first truly deliberate behavior appears the child can separate the means from purpose and follow a particular goal.

During the third stadium a child can produce desired effects only after it accidentally stumbles upon them. This limitation disappears in the forth stadium, when a child first notices the desired goal, and then thinks of ways to accomplish it. By doing this, the child demonstrates it's first truly deliberate behavior.

Fifth stadium: Novelty and exploration (from twelfth to eighteenth month)

Child begins to systematically change schemata in order to produce new effects. Problems are solved through the active process of trial and error.

Piaget calls the fifth stadium "discovering new means through active exploration." The word new signifies the main difference the forth and fifth stadium. In the forth stadium the child uses mostly known schemata in order to produce smaller number of known effects. As opposed to that, during the fifth stadium the child begins to systematically and through planning change its behavior thus creating new schemata and new effects. 
Sixth stadium: Mental imaging (from eighteenth to twenty-fourth month)

Ability to imaginate or function symbolically appears. Mental problem solving replaces the problems of trial and error.

During the first five sub-stadiums, the child's entire adjustments to the world occurs through external behavior. Even in the fifth stadiums, child's problem solving is based on examination of one behavior after another until solution is reached. Advancement that occurs in the sixth stadium is based on the fact that child becomes able to imaginate something for the first time,i.e. It is able to think and plan an activity from the inside, not through external activity. This advancement also signifies the end of sensory-motoric period.

\section{COGNITIVE PROCESSES IN MATHEMATICAL THINKING}

It is a fact that only hereditary, i.e. genetic factors are not sufficient for development of a child's brain; on the contrary, a child needs external stimuli expressed through touch, speech, images, which leads to the conclusion that immediate and extended surroundings shape the brain, meaning that the external stimuli, stronger or weaker, mutually connect the brain cells and neurons.

Every research brings new facts which point to mistakes we made while raising children so far. Dryden and Wass (2001, p. 242) explains why babies should be exposed to watching sharp contrasts.

During the first months, a baby's brain asserts its "optical tracts". Child's cortex has six layers of cells which transmit different signals from the retina in the optical neuron into the brain. For example, one layer of those cells transmits signals for horizontal lines and another for vertical ones.
Other layers or columns of cells are engaged with circles, squares and triangles.

If a child could see only horizontal lines, for example, it would then constantly collide with legs of tables and chairs while crawling or walking because its "optical tracts" would not be able to process vertical lines.

American scientists, Torstein Wiesel and David Hubel, won the Nobel prize because they proved that such an early sensory experience is a key factor in 'teaching' nerve cells their roll.

Koutlak (1996) claims: „Even in a case of a perfect brain in a person, they will not be able to see unless the brain processes visual stimuli until the age of two, and they will never learn to speak unless they heard speech by the age of ten.

According to numerous research conducted so far ( Birkenbihl V. B., 1989). Psychologisch richtig verhandeln. Mgv. Landsberg) we can roughly distinguish two brains - 'the older' and 'the younger'.

Our biological program is placed in the older brain', "the hardware" the functionality of which is responsible for empiricism, avoiding pain and discomfort, it motivates or reduces the urge to escape, it ensures survival instinct, instinct to satisfy vital needs, it manages and controls our behavior, blocks our thinking, influences the perception of reality, controls our body movement.

'The old brain' represents the headquarters of our feelings, emotionality, it contains and preserves our memories. This is where our Id (Freud) and childish I (Berne), our super-conscious and sub-conscious, chaos and many unexplored things are.

'The young brain' afore mentioned division is an integral part of the left and the right hemispheres, cerebral cortex, and it represents "softwares" with functions and tasks to connect, analyze, conclude, think about oneself, explore oneself, satisfy typical 
human needs, and includes intelligence and creativity (Brajša, 1995, p. 53).

There is no device for creating patterns that is remotely similar to the brain. The brain has an ability to literally preserve each and every major information that reaches it.

If, for example, one learns to identify and recognize a dog, the brain will establish a dossier for dogs. Every other type of dog that one learns to recognize will be memorized into a similar system of patterns. The same analogy follows for birds, horses, cars, jokes and every other thing. Today, many scientists believe that the human brain all these interconnected information saves in the form of branches in a tree.

However, the matter is even more complicated. If one was to be asked to name types of apples you know, they would start naming them from their tree for memorizing 'apples': red crème d'Elicious, gold crème d'Elicious, Granny Smith, etc. If one was asked to name all the fruit they know, apples would then be in a container with oranges, pears and grapes in their tree for "memorizing" fruit.

If one was asked to name round objects in that case, oranges would be included in the process of naming because they belong to the tree for memorizing 'round objects'. Hence, a person's brain classifies information in a multitude of different memorizing dossiers, similar to a library, index of a book, or a book of inter-references (Dryden and Wass, 2001, p. 132). these micro contemplations will be concluded with the constatation:,"The least explored territory in the world is the space between our ears".

Thanks to this "device" which weighs cca $1300 \mathrm{~g}$ proteins, blood and adipose tissue, we are able to think, make decisions, react, dream, and especially we can learn.
And what is learning?

There are still no adequate definition which would wholly encompass the given term with its content, precision and brevity.

"Learning is a process which comes to life based on interaction with the surroundings or the reaction to a particular situation and becomes a relatively permanent behaviour or undergoes changes, during which changes conditioned through inherent ways of reacting, the maturation process or temporary state of the body (tiresome, drunkenness, etc.) should be excluded" ( Skowronek, 1970).

It is an indisputable fact that all forms of learning can be characterized as learning with or without understanding. Learning with understanding is in its core based on previously determined factors and ideas, as well as clearly defined goals in "cognitive structure", while learning without understanding occurs accidentally and is not supported by the individual's ideas. The mere title "Cognitive Processes of Mathematical Thinking" mostly is based on natural learning process, however, this paper deals with deeper set of problems, which are not only difficult to resolve but possibly there is no resolution. Namely, a question is posed what is the appropriate age when a child is ready and able to solve certain mathematical problems or notice mathematical principles, that is, whether they are actually exist clearly defined age boundaries based on which a conclusion could be made about the time and individual is ready to solve mathematical problems of a concrete difficulty level or to notice mathematical laws.

According to Jean Piaget, development of thinking can be roughly divided into four broad periods, in the manner that each new period leans on the previous one by the pattern "Where I stopped you will continue; what I have could not have done, you will". 
Based on researches which were mostly conducted through experiment, Piaget creates a scale based on age and singles out the first period or the sensory-motoric period which lasts from birth till approximately eighteen months.

The basic characteristic of this period is that a baby manages to connect emotion with action, existence of objects is conditioned by seeing them, while in a more mature stadium the baby becomes aware of the existence of an object even without seeing it, and also becomes aware of the reversibility.

The second period, lasting from the eighteenth month through the seventh year is named by Piaget as a pre-operative stadium, which he divides into two sub-periods, $2 \mathrm{a}$ and $2 \mathrm{~b}$. Both parts have their own features which are characteristic of children's behaviors and seeing the world through children's eyes, especially in the period $2 \mathrm{a}$, when the child solves problems intuitively. Logic becomes prominent in phase $2 \mathrm{~b}$, when a conflict occurs between the child's perception and ability to logically reason.

The third period includes years seven to twelve and it is the so called concrete-operative period where logical reasoning is even more prominent, even though this period is still based on immediate perceptions or earlier experiences.

A child understands the notion of commutativity in the operation of adding and the notion of reversibility, which enables it to conclude, for example, $7-3=4$, because $3+4=7$, even though the child does not connect the opposition of the mentioned operations. It is also interesting that in this period the child understands the notion of transitivity in the form $\mathrm{A}=\mathrm{B}, \mathrm{B}=\mathrm{C} \rightarrow \mathrm{A}=\mathrm{C}$, or $\mathrm{A}>\mathrm{B}$, $\mathrm{B}>\mathrm{C} \rightarrow \mathrm{A}>\mathrm{C}$, while in task of the type "Emir is taller than Goran, Goran is taller than Zlatan; who is the tallest?", children are not ready to provide the correct answer. Piaget sees this inability in the fact that logic assumes greater and greater role in thinking, but it is still mostly reliant in looking for solutions based on perception.

The forth period is marked by abilities to handle hypothetical theses, deductive conclusions, logical reasoning, etc.

An interesting matter occurs prominently here and is manifested in the fact that children think strictly hypothetically, without even considering the possibility of practical realization of the problem. An example of this is: if 15 eggs cost $2 \mathrm{KM}$, how many eggs can be bought for $1 \mathrm{KM}$ ? Children's response is 7,5 , but they are not at all interested whether the given problem can be realized in practice.

Dilemmas of the importance can be shown in the following example:

Let us ask ourselves what is more important for a child, to understand that $7 \times 2$ is the same $2 \times 7$, or to memorize that $2 \times 7=14$ ? In fewer words, is it more important that a child can calculate or understand? Exactly in these obviously bizarre matters the dilemma occurs.

"When we teach the calculation skills, we are asked to understand, when we teach the skill of understanding, we are asked to calculate" (Liebeck, 1984).

Regardless of therequests of this galloping, demanding, competition-wise, thoughtless phenomenon named globalization of society, it should not be forgotten that every child should unprincipled visually experience every mathematical problem, of course, if that is a possibility (arranging dice, grouping sticks together, playing educational games such as tangram, abacus, etc.) and only register the image which should be sketched based on the visual experience (the form of a square, triangle, circle, etc.) and then to conjoin the sketched elements with symbols, i.e. numbers. 
"The aim is to assign a symbolic representation with the meaning which is encompassed in the concrete representation.

Unavoidable fact is "that children are born intelligent" and that even before enrolling in school most of them are familiar with elementary mathematical operations such as adding, subtracting, multiplying and dividing, of course, parents are extremely satisfied since they are in great part the ones who helped the development of physical as well as intellectual levels of their children. The notion of number expressed in the form of a figure as well as mathematical operations, are based on memorizing and reproduction in children, thus since they are acquired as such they cannot represent fertile soil for developing creative thinking and resourcefulness in unfamiliar situations, and mathematics is abundant with those. Seldom does a parent ask himself or herself "how does my child accept abstract notions such as what is a number or a certain operation."

It is a very frequent occurrence that a great number of high school students, due to the abstractness of their notions of operations accept the mathematical formulation $2 \mathrm{a}+2 \mathrm{~b}$ as $4 \mathrm{ab}$ or in some other way.

Why do we "run away" from notions of apples and pears, why do we leave out bundles of ten sticks, where are abacuses with black, white and red marbles? During the last several years the methodology department from the Pedagogy Academy in Zenica, lead by teacher Nihad Suljčić, PhD, has been conducting intensive education of the teaching staff through tangrams, abacuses, numbered dices, and similar teaching aids with the goal to connect the subject matter more firmly with simpler general representations, which would at least to a certain point help the realization of elementary didactic principles of learning mathematics such as:
- Avoid hypothetical and didactic manner of thinking in students in lower grades.

- Gradually transfer concrete and obvious manners to abstract and symbolic.

- Enable those students with difficulties in understanding the subject matter a return to concrete level or helped them by inserting a phase-in-between which would help them get acquainted with the content of activities to come.

- Apply multiple repetition.

- Point out the important elements and marginalize the unimportant ones.

- Cover the characteristic features of operations, as well as elements of interconnections through multiple analogies and universality.

- Pay attention to the way that obvious means reduce in effect in regard to their generalization.

- Notice the important principles from the viewpoint of their application.

- Try to avoid the examples that create dilemma or are trivial in nature.

- While covering any mathematical operation it is desirable to explicitly formulate it through language, which leads to integration to previous experiences, and achieves the affect of keeping track of tracts between obvious representations and technical term. Research of Piaget's theses that activities of thinking are rooted in transference and copying realistic activities being performed material objects are continued by Galperin and Lompsher who, together with Bruner, reach constatation that mental activities occur several interconnected levels. 
1. Level of practical - objective activities which enables applicability of a possible object of knowledge.

2. Level of immediate observation - it is important to mention that in this case not only the mere observation of object is significant, but also the fulfillment of the observed object in thought with the majority of its characteristics.

3. Level of indirect observation - on this level earlier memorized and comparative approach to the object is activated.

4. Level of linguistic - notional cognition, where mental activity is mostly performed within the frame of notional, that is, in the frame of the abstract and not direct structures.

"The four levels represent, on the one hand, a genetic order, where the higher level is developed from the lower one as its basis. On the other hand, the lower levels do not cease to exist, but all the planes that were once created continue to exist, and new planes influence the previous ones, thus changing their character. Among all four planes there are interrelations, and they constantly change during development" .

Prior research, as well as practices, have shown a far better efficiency in grasping a particular operation when it is combined with other operations. It is recommended to parallelly perform adding and subtracting when teaching multiplying, such as

$$
6 \times 9=9 \times 6=9 \times 5+9 \times 1=10 \times 6-1 \times 6 \text { etc. }
$$

Tasks presented or similar manner develop in students the sense of flexibility, combinatorics, freedom, which contributes to much faster and simpler learning or multiplying table, because the student is provided with the possibility of choosing different ways to achieve the end goal.

On the other hand, the receptive form of learning, where the student is left to his or her own devices to explore and come up with the most optimal paths to the goal is proving very efficient: "Students should construct their knowledge's through their own activities, to individually search for facts and relations, and productively use their previous knowledge in order to expend what they already know".

\section{CONCLUSION}

In relation what has been mentioned, it is important to point out that only one type of learning is rarely employed, but different types intertwine and mutually complete one another, thus in mathematics we mostly encounter the following types of learning:

1. Associative learning (learning based on signals, stimuli, which transform into automatism, such as multiplying table, operations with fractions, solving equations, etc.)

2. Discriminatory learning (based on nourishing the ability to discriminate between different, but also similar things as notions, such as a square, a rectangle, etc.)

3. Learning mathematical terms (axiomatically form certain terms and learn more complex ones based on them)

4. Learning mathematical rules (definition, theory, theorem)

5. Learning heuristic rules (learning with understanding, distinguishing receptive from cognitive, deciding what is given and what is asked for, as well as if the path is correct)

6. Solving mathematical problems (learning through solving mathematical relations, working on typological and constructive tasks)

7. Learning by observation (even though it is similar to the relation of the demonstrated, imitated-demonstrated, still has its advantages (Bandura, 1977). 


\section{REFERENCES}

- $\quad$ Bandura, A. (1977). Social Learning theory. Englewwood Cliffs, $\mathrm{Nj}$ : Pretince Hall.

- Birkenbihl V. B. (1989). Psychologisch richtig verhandeln. Mgv. Landsberg

- Brajša, P. (1995). Sedam tajni uspješne škole [Seven secrets of successful schools]. Zagreb, Croatia: Školske novine.

- Dryden, G., Wass, J. (2001). Revolucija u исеenju [A revolution in learning]. Zagreb, Croatia: Educa.

- Kotulak, R.(1996). Inside The Brain. Published by Andrewsand McMeel

- Liebeck, P. (1984). Kako djeca uče matematiku [How children learn mathematics]. Zagreb: Educa.

- $\quad$ Skowronek, H. (1970) Lernen und Lernfähigkeit - 2. Aufgabe [Learning and learning ability - 2 Task]. München: Juventa. 